\title{
A new method for the preparation of solvatochromic 5-(5-X-6- hydroxynaphthyl-2)-7H-indolo[1,2-a]quinolinium merocyanines
}

\author{
Marta J. Sawicka*, Jacek A. Soroka and Monika Gąsiorowska \\ West Pomeranian University of Technology, Institute of Chemistry and Environmental Protection, Section of Instrumental \\ Analysis, Szczecin, ul. Piastów 42, 71-065 Szczecin, Poland \\ *Corresponding author: e-mail: msawicka@zut.edu.pl
}

\begin{abstract}
A new method for the preparation of $7 \mathrm{H}$-indolo[1,2-a]quinolinium solvatochromic dye precursors has been investigated. 5-(6-Hydroxynaphthyl-2)-7,7-dimethyl-7H-indolo[1,2-a]quinolinium perchlorate, 5-(5-bromo6-hydroxynaphthyl-2)-7,7-dimethyl-7H-indolo[1,2-a]quinolinium perchlorate and 5-(5-nitro-6hydroxynaphthyl-2)-7,7-dimethyl-7H-indolo[1,2-a]quinolinium perchlorate were obtained via demethylation of the corresponding 5-(5-X-6-methoxynaphthyl-2)-7,7-dimethyl-7H-indolo[1,2-a]quinolinium salts. The application of pyridinium hydrochloride in the demethylation of the methoxy perchlorates allowed to obtain the products with the almost quantitative yield in a very short time, especially when the reaction was carried out using microwave irradiation.
\end{abstract}

Keywords: 7H-indolo[1,2-a]quinolinium perchlorate, solvatochromic dye, pyridinium hydrochloride, microwave synthesis, demethylation

\section{INTRODUCTION}

Continuous interest in solvatochromic dyes results from their applicability in different fields, e.g. for the determination of the polarity of solvents ${ }^{1}$ or solid surfaces employed as stationary phases in chromatography ${ }^{2}$, for the characterisation of polymers ${ }^{3}$, organized media $^{4}$ and supercritical fluids ${ }^{5}$ as well as in the analysis of solventdependent kinetic and thermodynamic processes occurring in mixed solvents ${ }^{6}$, to monitor the presence of some metal ions (i.e. cobalt, copper and iron) $)^{7}$, and in quantitative analysis of binary and ternary solvent mixtures ${ }^{8}$.

Among numerous compounds exhibiting solvatochromic properties, derivatives of hydroxyaryl-7H-indolo[1,2a]quinolinium cation ${ }^{9-12}$ play an important role. These merocyanine-like dyes are generated in situ treating corresponding hydroxy perchlorates with anhydrous potassium carbonate. The $\mathrm{pK}_{\mathrm{a}}$ value of the salts influences the facility of this process. The preferred, low $\mathrm{pK}_{\mathrm{a}}$ were obtained when an electron-withdrawing substituent, such as the nitro group or bromine atom, was present especially in the ortho position in respect to the hydroxyl group ${ }^{10}$.

5-(6-Hydroxynaphthyl-2)-7,7-dimethyl-7H-indolo[1,2a]quinolinium merocyanine is the most sensitive solvatochromic compound among the whole group of $7 \mathrm{H}-$ indolo[1,2-a]quinolinium dyes. This compound was synthesized by demethylation of 5-(6-methoxynaphthyl-2)-7,7dimethyl-7H-indolo[1,2-a]quinolinium perchlorate using hydrobromic acid solution in acetic acid. The process lasted 28 hours and yielded only $16 \%$ of the target product ${ }^{11}$, which is unacceptable from a practical point of view.

Among several reagents used for demethylating methyl aryl ethers ${ }^{13}$ the most common ones are $\mathrm{BBr}_{3}, \mathrm{AlCl}_{3}$, pyridinium hydrochloride and hydrogen bromide dissolved in acetic acid. Pyridinium hydrochloride seems to be really attractive due to its low cost and ready availability. Moreover, the high polarity of pyridinium hydrochloride allows to replace conventional heating with microwave irradiation $^{14}$ which in various organic synthesis can distinctly accelerate a reaction and influence the yield, selectivity and direction of the reaction ${ }^{15}$.
In the present paper a new method for the preparation of 5-(5-X-6-hydroxynaphthyl-2)-7,7-dimethyl-7Hindolo[1,2-a]quinolinium perchlorates is presented. The new procedure consists in the application of pyridinium hydrochloride as an effective demethylating agent of the corresponding 5-(5-X-6-methoxynaphthyl-2)-7,7-dimethyl$7 \mathrm{H}$-indolo[1,2-a]quinolinium salts. The experiments are conducted under conventional heating or microwave irradiation.

\section{EXPERIMENTAL SECTION}

\section{Instruments and laboratory equipment}

Microwave irradiation was carried out using a household microwave oven equipped with a rotating plate, Moulinex, $700 \mathrm{~W}$ operating at $2.4 \mathrm{GHz}$.

The stirring of the reagent mixture (thermal activation) was done with a polygon teflon-coated magnetic stirring bar by the use of IKAMAG RCT basic magnetic stirrer equipped with an ETS-D fuzzy IKATRON electronic contact thermometer.

The melting points were determined with a Büchi SMP20 apparatus and are uncorrected.

The elemental analysis was carried out using the Euro EA analyzer.

The NMR spectra were recorded using a DPX 400 Bruker (400 MHz) spectrometer. The positions of particular signals [ppm] and the $J$ values [Hz] were read out directly from the original spectra.

The IR spectra were recorded with a computer-controlled spectrophotometer Specord M80 (Carl Zeiss Jena, Germany) modified by MEDSON ${ }^{16}$, by the $\mathrm{KBr} / \mathrm{Nujol}$ technique, in the range of $400-4000 \mathrm{~cm}^{-1}$.

The UV-VIS spectra were recorded with a computercontrolled spectrophotometer Specord M40 (Carl Zeiss Jena, Germany) modified by MEDSON ${ }^{16}$, in the range of $12000-49000 \mathrm{~cm}^{-1}$ at $25 \pm 0.1^{\circ} \mathrm{C}$. Gas-tight quartz cells $(1 \mathrm{~cm})$, automatically adjustable pipettes with the volume $100-1000$ and $1000-5000 \mathrm{ml}$ from PZ HTL Co., 
and the liquid $10 \mu \mathrm{l}$ syringe from Hamilton-Bonaduz, were used.

The $\mathrm{pH}$-measurements were carried out by means of Checkmate II Corning pH-meter (Aldrich, Cat. No. 473017).

\section{Solvents and reagents}

The $99 \%$ acetic acid, bromine, anhydrous potassium carbonate, pyridine $99 \%$, and hydrochloric acid $35-38 \%$ were purchased from POCH - Gliwice (Poland). The 99.5\% nitric acid from Merck was used. The distilled water was obtained using a Büchi glass apparatus and used without additional purification.

Pyridinium hydrochloride was obtained according to the classical method by water evaporation from pyridine and hydrochloric acid (heating from $100^{\circ} \mathrm{C}$ to ca. $190^{\circ} \mathrm{C}$ ).

5-(6-Methoxynaphthyl-2)-7,7-dimethyl-7H-indolo[1,2a]quinolinium perchlorate (1a) was synthesised according to the literature data ${ }^{11}$.

\section{Procedures:}

Synthesis procedures

5-(5-Bromo-6-methoxynaphthyl-2)-7,7-dimethyl-7Hindolo $[1,2-a] q u i n o l i n i u m$ perchlorate (1b): 5-(6methoxynaphthyl-2)-7,7-dimethyl-7H-indolo[1,2a]quinolinium perchlorate (1a) $(0.30 \mathrm{~g}, 0.60 \mathrm{mmol})$ was dissolved in boiling glacial acetic acid $(15 \mathrm{ml})$, then the solution of bromine in glacial acetic acid $(0.04 \mathrm{ml}(0.72$ mmol) $\mathrm{Br}_{2}$ and $2 \mathrm{ml} \mathrm{AcOH}$ ) was added dropwise with stirring and heating under reflux for 15 minutes and additionally stirred and refluxed for 20 minutes. A crude product which precipitated after cooling was isolated by filtration yielding $0.18 \mathrm{~g}(51 \%)$ of 5-(5-bromo-6methoxynaphthyl-2)-7,7-dimethyl-7H-indolo[1,2a]quinolinium perchlorate (1) as yellow powder, m.p. $291-293^{\circ} \mathrm{C}$ (from $\mathrm{AcOH}$ ). $\mathrm{C}_{29} \mathrm{H}_{23} \mathrm{BrClNO}_{5}$; $\mathrm{FW}$ 580.854; calculated: C (59.97\%) H (3.99\%) N $(2.41 \%)$, found: C $(59.76 \%) \mathrm{H}(3.97 \%) \mathrm{N}(2.42 \%)$.

${ }^{1} \mathrm{H}$ NMR $\left(400 \mathrm{MHz}, \mathrm{CDCl}_{3}, \mathrm{TMS}\right): \delta_{\mathrm{H}}(\mathrm{ppm})(\mathrm{J}(\mathrm{Hz}))$ $1.95\left(\mathrm{~s}, 6 \mathrm{H}, \mathrm{CH}_{3}\right), 4.18\left(\mathrm{~s}, 3 \mathrm{H}, \mathrm{OCH}_{3}\right), 7.83(\mathrm{~d}, 1 \mathrm{H}$, $J=9.2$, H-7'), $7.90-7.95$ (m, 2H, H-10, H-8), 8.08 (dd, $1 \mathrm{H}, J_{1}=8.8 ; J_{2}=1.4, \mathrm{H}-3$ '), $8.16-8.22(\mathrm{~m}, 2 \mathrm{H}, \mathrm{H}-3, \mathrm{H}-9)$, $8.41\left(\mathrm{~d}, 1 \mathrm{H}, J=9.1, \mathrm{H}-\mathbf{8}^{\prime}\right), 8.45-8.53\left(\mathrm{~m}, 3 \mathrm{H}, \mathrm{H}-4^{\prime}\right.$, H-4, H-2), 8.56 (s, 1H, H-6), 8.92 (d, 1H, H-1'), 9.08 (d, $1 \mathrm{H}, J=8.6, \mathrm{H}-11), 9.54$ (d, $1 \mathrm{H}, J=8.9, \mathrm{H}-1)$.

IR $\left(\mathrm{cm}^{-1}\right)$ : 1073, 1252, 1577, 1717.

UV-VIS $\left(\mathrm{CH}_{3} \mathrm{CN}, \quad \mathrm{c}=2 \cdot 10^{-5} \mathrm{~mol} \cdot \mathrm{dm}^{-3}\right): \bar{v}_{\max }\left(\mathrm{cm}^{-1}\right) /$ $\log \varepsilon$ 24227/4.206, 32638/4.016.

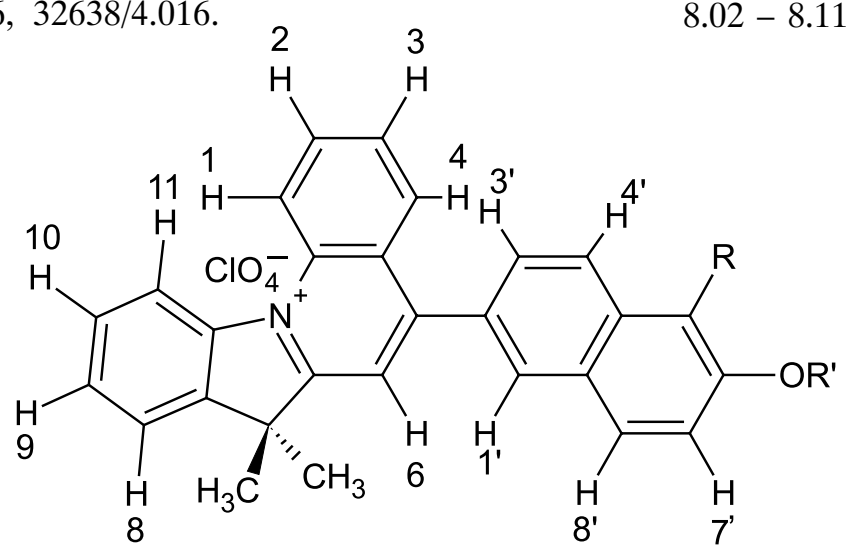

$\mathrm{R}=\mathrm{H}(\mathbf{a}), \mathrm{Br}(\mathbf{b})$ or $\mathrm{NO}_{2}(\mathbf{c})$

$\mathrm{R}^{\prime}=\mathrm{CH}_{3}(1)$ or $\mathrm{H}(2)$ $J=8.9$, H-11), 9.55 (d, 1H, $J=9.3$, H-1).
5-(5-Nitro-6-methoxynaphthyl-2)-7,7-dimethyl-7Hindolo[1,2-a]quinolinium perchlorate (1c): 1a $(0.30 \mathrm{~g}$, $0.60 \mathrm{mmol})$ was dissolved in boiling glacial acetic acid $(17 \mathrm{ml})$, then the solution of nitric acid in acetic acid $\left(0.04 \mathrm{ml}(0.92 \mathrm{mmol})\right.$ of fuming $\mathrm{HNO}_{3}$ and $1 \mathrm{ml}$ of $\mathrm{AcOH})$ was added dropwise stirring and heating under reflux for 20 minutes. Next, the reaction mixture was stirred and refluxed additionally for 10 minutes. The solution was cooled to the room temperature. The precipitate was filtered out, washed with acetic acid and methanol giving 5-(5-nitro-6-methoxynaphthyl-2)-7,7-dimethyl-7H-indolo[1,2-a]quinolinium perchlorate (1c) (0.23 g; yield $71 \%$ ) as yellow powder, m.p. $300-302^{\circ} \mathrm{C}$ (from AcOH); $\mathrm{C}_{29} \mathrm{H}_{23} \mathrm{ClN}_{2} \mathrm{O}_{7} ; \mathrm{FW}$ 546.955; calculated: $\mathrm{C}$ (63.68\%) H (4.24\%) N (5.12\%), found: C (63.94\%) H $(4.22 \%) \mathrm{N}(5.14 \%)$.

${ }^{1} \mathrm{H}$ NMR $\left(400 \mathrm{MHz}, \mathrm{CDCl}_{3}, \mathrm{TMS}\right): \delta_{\mathrm{H}}(\mathrm{ppm})(\mathrm{J}(\mathrm{Hz}))$ $1.95\left(\mathrm{~s}, 6 \mathrm{H}, \mathrm{CH}_{3}\right), 4.23\left(\mathrm{~s}, 3 \mathrm{H}, \mathrm{OCH}_{3}\right), 7.90-7.93(\mathrm{~m}$, 2H, H-9, H-7'), 8.00 - 8.04 (m, 2H, H-10, H-8), 8.12 (dd, $\left.1 \mathrm{H}, J_{1}=8.8, J_{2}=1.3, \mathrm{H}-3^{\prime}\right), 8.16-8.21(\mathrm{~m}, 2 \mathrm{H}, \mathrm{H}-3$, H-4'), 8.45 - 8.49 (m, 2H, H-4, H-2), 8.63 (d, 1H, J=9.3, H-8'), 8.66 (s, 1H, H-6), 8.94 (d, 1H, H-1'), 9.09 (d, 1H,

IR $\left(\mathrm{cm}^{-1}\right): 915,1074,1256,1505,1581$.

UV-VIS $\left(\mathrm{CH}_{3} \mathrm{CN}, \mathrm{c}=2 \cdot 10^{-5} \mathrm{~mol} \cdot \mathrm{dm}^{-3}\right): \bar{v}_{\max }\left(\mathrm{cm}^{-1}\right) /$ $\log \varepsilon$ 25527/4.230, 29775/4.073.

\section{General demethylation procedure}

5-(5-X-6-methoxynaphthyl-2)-7,7-dimethyl-7Hindolo[1,2-a]quinolinium perchlorate $(0.05 \mathrm{mmol})$ and pyridinium hydrochloride $(2.5 \mathrm{mmol})$ were heated under reflux (Method A) for 20 minutes or irradiated with microwaves (Method B) for two 1-minute intervals in a stoppered round-bottomed conical flask with the capacity of $100 \mathrm{ml}$. Next water was added and the precipitate was filtered out, washed several times with water and dried in the air.

5-(6-Hydroxynaphthyl-2)-7,7-dimethyl-7H-indolo[1,2a]quinolinium perchlorate (2a): from 1a; yield: method A: $84 \%$, method B: $88.5 \%$; dark yellow powder, m.p. 265 - $267^{\circ} \mathrm{C}$ (from $\mathrm{CH}_{3} \mathrm{NO}_{2}$ ) (lit. $268-270^{\circ} \mathrm{C}$ [11]); $\mathrm{C}_{28} \mathrm{H}_{22} \mathrm{ClNO}_{5}$; $\mathrm{FW} 487.931$; calculated: $\mathrm{C}(68.92 \%) \mathrm{H}$ (4.54\%) N (2.87\%), found: C (68.66\%) H (4.52\%) N $(2.86 \%)$.

${ }^{1} \mathrm{H}$ NMR $\left(400 \mathrm{MHz},\left(\mathrm{CD}_{3}\right)_{2} \mathrm{SO}, \mathrm{TMS}\right): \delta_{\mathrm{H}}(\mathrm{ppm})$ $(J(\mathrm{~Hz})) 1.89\left(\mathrm{~s}, 6 \mathrm{H}, \mathrm{CH}_{3}\right), 7.27$ (dd, 1H, J=8.8, H-7'), 7.31 (d, 1H, H-5'), 7.74 - 7.79 (m, 3H, H-8, H-9, H-10), $8.02-8.11$ (m, 4H, H-3, H-3', H-4', H-8'), 8.26 (s, 1H,

Scheme 1. The structures of $2 \mathbf{a}, \mathbf{2 b}$ and $2 \mathbf{c}$ 
H-6), 8.39 (t, 1H, J=7.5, H-2), 8.48 (d, 1H, J=7.7, H-4), 8.77 (d, 1H, H-1'), 8.95 (d, 1H, J=8.0, H-11), 9.40 (d, 1H, $J=8.7, \mathrm{H}-1), 10.37$ (s, 1H, OH).

IR $\left(\mathrm{cm}^{-1}\right)$ : 870, 1074, 1185, 1287, 1581, 3269.

UV-VIS $\left(\mathrm{CH}_{3} \mathrm{CN}, \mathrm{c}=2 \cdot 10^{-5} \mathrm{~mol} \cdot \mathrm{dm}^{-3}\right): \bar{v}_{\max }\left(\mathrm{cm}^{-1}\right) /$

loge 23731/4.154, 29946/4.007.

$\mathrm{pK}_{\mathrm{a}}=8.08$

solvatochromic shift $\Delta \bar{v}_{\max }($ trichloroethylene - water $)$

$=8152 \mathrm{~cm}^{-1} \mathbf{1 1}$.

5-(5-Bromo-6-hydroxynaphthyl-2)-7,7-dimethyl-7Hindolo[1,2-a]quinolinium perchlorate $(2 \mathbf{b})$ : from $\mathbf{1 b}$; yield: method A : $72 \%$, method B: $86 \%$; dark yellow powder, m.p. $285-286^{\circ} \mathrm{C}$ (from $\mathrm{AcOH}$ ). $\mathrm{C}_{28} \mathrm{H}_{21} \mathrm{BrClNO}_{5}$; FW 566.827; calculated: C (59.33\%) H (3.73\%) N (2.47\%), found: C $(59.52 \%) \mathrm{H}(3.74 \%) \mathrm{N}(2.46 \%)$.

${ }^{1} \mathrm{H}$ NMR (400 MHz, DMSO, TMS): $\delta_{\mathrm{H}}(\mathrm{ppm})(\mathrm{J}(\mathrm{Hz}))$ 1.80 (s, 6H, CH3), 7.52 (d, 1H, J=8.6, H-7'), $7.74-7.76$ (m, 2H, H-10, H-8), 7.89 (dd, 1H, J=8.3, H-3'), 8.01 8.03 (m, 3H, H-8', H-3, H-9), 8.26 - 8.41 (m, 4H, H-4', H-4, H-6, H-2), 8.77 (d, 1H, H-1'), 8.92 (d, 1H, J=5.4, H-11), 9.39 (d, 1H, J=8.3, H-1), 11.15.(s,1H, OH).

IR $\left(\mathrm{cm}^{-1}\right): 815,1079,1236,1282,1578,1707,3395$. UV-VIS $\left(\mathrm{CH}_{3} \mathrm{CN}, \mathrm{c}=2 \cdot 10^{-5} \mathrm{~mol} \cdot \mathrm{dm}^{-3}\right): \bar{v}_{\text {max }}\left(\mathrm{cm}^{-1}\right) /$

loge 24336/4.209, 29859/4.112.

$\mathrm{pK}_{\mathrm{a}}=7.27$

solvatochromic shift $\Delta \bar{v}_{\max }($ trichloroethylene - water $)$

$=8240 \mathrm{~cm}^{-1}$

5-(5-Nitro-6-hydroxynaphthyl-2)-7,7-dimethyl-7Hindolo[1,2-a]quinolinium perchlorate (2c): from 1c; yield: method A 92\%; green powder, m.p. $283-286^{\circ} \mathrm{C}$ (from $\mathrm{AcOH}$ ); $\mathrm{C}_{28} \mathrm{H}_{21} \mathrm{ClN}_{2} \mathrm{O}_{7} ; \mathrm{FW}$. 532.928; calculated: $\mathrm{C}(63.10 \%) \mathrm{H}(3.97 \%) \mathrm{N}(5.26 \%)$, found: C $(63.26 \%) \mathrm{H}$ $(3.98 \%) \mathrm{N}(5.24 \%)$.

${ }^{1} \mathrm{H}$ NMR (400 MHz, DMSO, TMS $): \delta_{\mathrm{H}}(\mathrm{ppm})(J(\mathrm{~Hz}))$ 1.80 (s, 6H, $\left.\mathrm{CH}_{3}\right), 7.67$ (d, 1H, J=9.0, H-7'), $7.72-7.75$ (m, 2H, H-9, H-10), 7.84 (d, 1H, J=8.4, H-8), 7.93 (dd, $\left.1 \mathrm{H}, J=8.8, \mathrm{H}-3^{\prime}\right), 8.01-8.05$ (m, 2H, H-3, H-4'), 8.26 (d, $1 \mathrm{H}, J=9.0, \mathrm{H}-8$ ') $8.31-8.36(\mathrm{~m}, 2 \mathrm{H}, \mathrm{H}-4, \mathrm{H}-2), 8.43(\mathrm{~s}$, 1H, H-6), 8.79 (d, 1H, H-1'), 8.94 (d, 1H, J=4.1, H-11), 9.40 (d, 1H, $J=8.6, \mathrm{H}-1), 11.23 .(\mathrm{s}, 1 \mathrm{H}, \mathrm{OH})$.

IR $\left(\mathrm{cm}^{-1}\right)$ : 747, 1078, 1236, 1579, 3307.

UV-VIS $\left(\mathrm{CH}_{3} \mathrm{CN}, \mathrm{c}=2 \cdot 10^{-5} \mathrm{~mol} \cdot \mathrm{dm}^{-3}\right): \bar{v}_{\max }\left(\mathrm{cm}^{-1}\right) /$

$\log \varepsilon$ 25811/4.271, 29729/4.164.

$\mathrm{pK}_{\mathrm{a}}=4.66$

solvatochromic shift $\Delta \bar{v}_{\max }$ (trichloroethylene - water)

$=7572 \mathrm{~cm}^{-1}$

\section{$p K_{a}$-Determination}

$\mathrm{pK}_{\mathrm{a}}$-Determination was performed in a mixture of 50 $80 \mu \mathrm{l}$ of the concentrated dye solution in DMSO (5 mg of the perchlorate in $700 \mu \mathrm{l}$ of anhydrous DMSO), $7 \mathrm{ml}$ of water and $1 \mathrm{ml}$ of methanol (due to poor solubility of the salts in neat water). The concentrations of these solutions were adjusted to keep the optical density below 1.4. The changes in the $\mathrm{pH}$ were achieved by adding microdoses of either $72 \%$ perchlorate acid or conc. aq. solution of sodium hydroxide. UV-VIS spectra were recorded in the range of $12000-27000 \mathrm{~cm}^{-1}$ at $22 \pm 1^{\circ} \mathrm{C}$.

\section{RESULTS AND DISCUSSION}

The demethylation of 5-(5-X-6-methoxynaphthyl-2)-7,7dimethyl-7H-indolo[1,2-a]quinolinium perchlorates proceeds according to Scheme 2.

In our earlier work ${ }^{\mathbf{1 1}}$ the solution of hydrogen bromide in glacial acetic acid was applied for the demethylation of 1a to 2a. The process appeared to be time-consuming (lasted 28 hours) and low-yielded (only 16\%) which limits potential application of strongly solvatochromic $\mathbf{2 a}$. In order to improve the obtained results the new procedure with the use of pyridinium hydrochloride applied as a demethylating agent has been investigated.

The new procedure was applied to the preparation of three compounds: 5-(6-hydroxynaphthyl-2)-7,7-dimethyl7H-indolo[1,2-a]quinolinium perchlorate (2a), 5-(5bromo-6-hydroxynaphthyl-2)-7,7-dimethyl-7H-indolo[1,2a]quinolinium perchlorate (2b), and 5-(5-nitro-6hydroxynaphthyl-2)-7,7-dimethyl-7H-indolo[1,2a]quinolinium perchlorate (2c). 5-(6-Methoxynaphthyl-2)7,7-dimethyl-7H-indolo[1,2-a]quinolinium perchlorate (1a) ${ }^{\mathbf{1 1}}$, was used as a starting material in the case of $\mathbf{2 a}$. In order to obtain $\mathbf{2 b}$ and $\mathbf{2 c}$ an additional step was performed before demethylation i.e. bromination or nitration of 1a to 5-(5-bromo-6-methoxynaphthyl-2)-7,7-dimethyl7H-indolo[1,2-a]quinolinium perchlorate (1b) or 5-(5nitro-6-methoxynaphthyl-2)-7,7-dimethyl-7H-indolo[1,2a]quinolinium perchlorate (1c), respectively (Scheme 3).

Bromination and nitration were carried out using the solution of molecular bromine or fuming nitric acid, respectively. In both cases monosubstituted perchlorates were obtained with the bromine atom or nitro group in 5position of the naphthalene moiety. Both bromination and nitration of 1a can lead to substituent introduction either into the naphthalene moiety or 7,7-dimethyl-7Hindolo[1,2-a]quinolinium system, however no substitution was observed in the $7 \mathrm{H}$-indolo[1,2-a]quinolinium system.

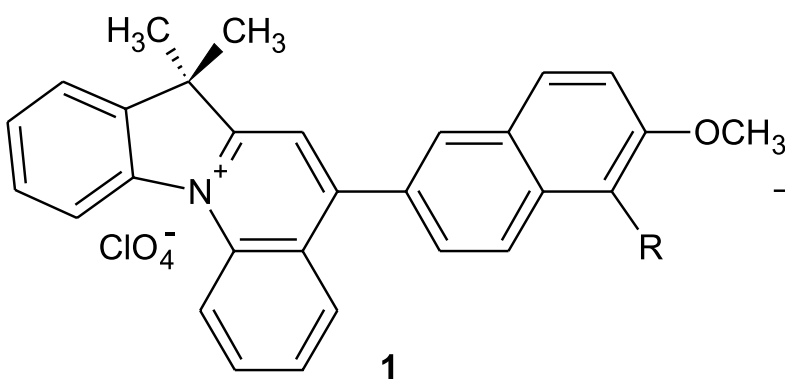

1

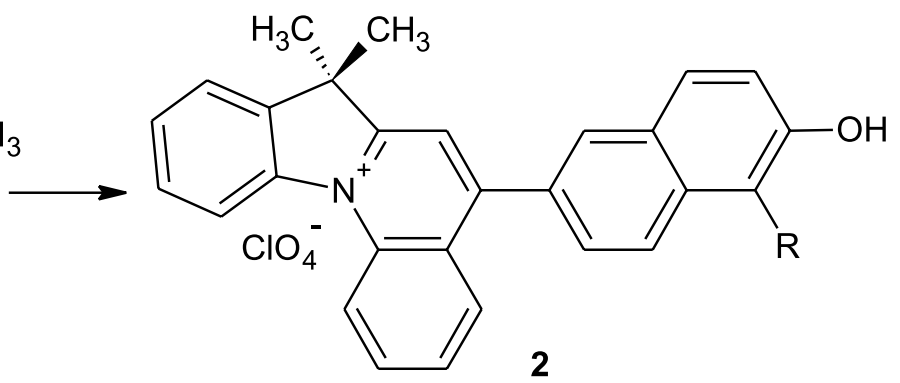

$\mathrm{R}=\mathrm{H}(\mathbf{a}), \mathrm{Br}(\mathbf{b}), \mathrm{NO}_{2}(\mathbf{c})$ 
<smiles>COc1ccc2cc(-c3cc4[n+](c5ccccc35)-c3ccccc3C4(C)C)ccc2c1</smiles>

(1a)

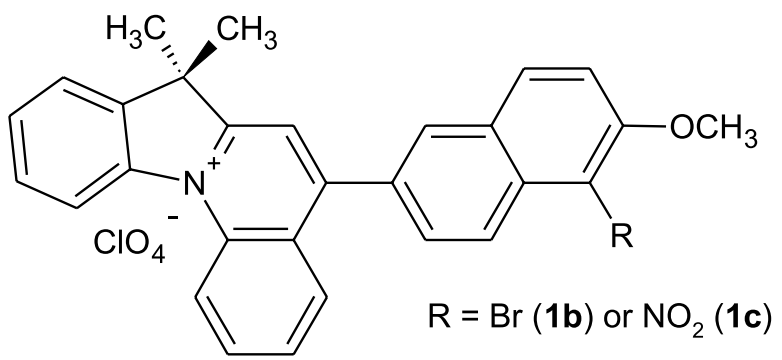

Scheme 3. Electrophilic aromatic substitution of 1a

The demethylation of $\mathbf{1 a}, \mathbf{1 b}$ and $\mathbf{1 c}$ was conducted in the refluxed pyridinium hydrochloride (conventional heating). The reaction progress was being monitored by an analysis of UV-VIS absorption spectra of 2a, since its properties are known in the literature ${ }^{\mathbf{1 1}}$.

The alkaline water solution of the methoxy (1a) and hydroxy (2a) derivatives distinctly differ in colour: the first one is yellow (the location of the absorption band c.a. $24000 \mathrm{~cm}^{-1}$ ) and the second one is red (the location of the absorption band c.a. $21000 \mathrm{~cm}^{-1}$ ). The reaction was considered to be completed as soon as the second band was present as sole. The UV-VIS spectra of the samples of the reaction mixture, taken after 2, 15 and 30 minutes of boiling and dissolved in water alkalised with potassium carbonate, are presented in Figure 1.

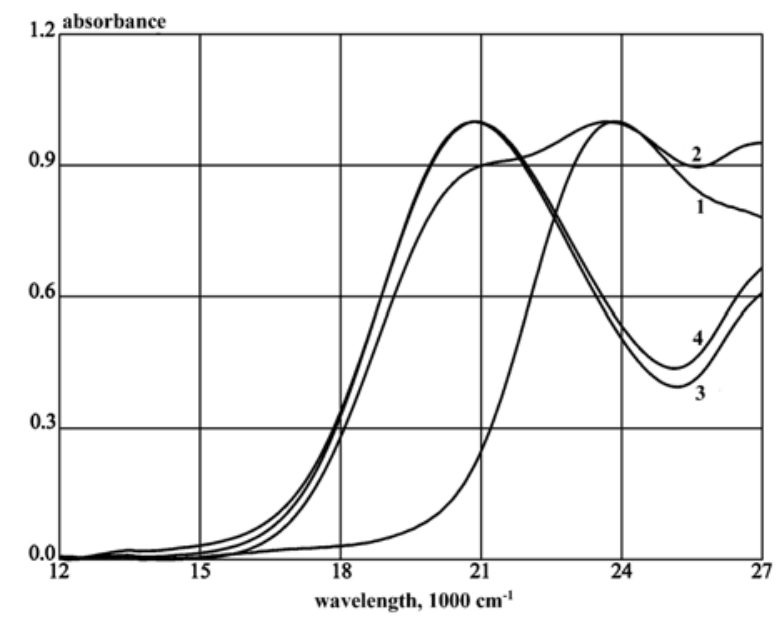

Figure 1. The normalized UV-VIS spectra of 1a and 2a after 0 (1), 2 (2), 15 (3) and 30 (4) minutes of boiling

Demethylation was completed after 15 minutes. Moreover, the reaction yield amounted to ca. $80 \%$ which is a great improvement in comparison with the literature data (Table 1).

Table 1. The comparison data of $\mathbf{1 a}$ demethylation by a different method

\begin{tabular}{|c|c|c|c|}
\hline Demethylating agent & Yield [\%] & Time & M.p. $\left[{ }^{\circ} \mathrm{C}\right]$ \\
\hline Hydrobromic acid ${ }^{11}$ & 16 & $28 \mathrm{~h}$ & $265-267$ \\
\hline Pyridinium hydrochloride & 84 & $15 \mathrm{~min}$. & $268-270$ \\
\hline
\end{tabular}

An alternative way of the $\mathbf{1 a}, \mathbf{1 b}$ and $\mathbf{1 c}$ demethylation is microwave irradiation of the reaction mixture consisting of corresponding methoxy perchlorates and pyridinium hydrochloride. The influence of microwaves on the reaction course is determined among others by solvent and reagents polarity, the changes in polarity during the reac- tion as well as the position of the transition state in respect to the ground state ${ }^{\mathbf{1 5}}$. The polarity is a very important factor since an absorption of the irradiation occurs according to dipolar polarization mechanism. When the polarity increases from the ground towards the transition state the stabilization of the transition state is more effective. It results in an enhancement of reactivity by a decrease in the activation energy. Therefore, a slight microwave effect is observed for instance in Diels-Alder cycloadditions, Cope rearrangement and ene reactions, in which the ground and the transition states are similar, but nucleophilic additions to the carbonyl compounds, $\mathrm{S}_{\mathrm{N}} 2$ reactions or Michael additions reveal specific microwave effect as the polarity evidently increases during the reaction course ${ }^{17}$. In the examined demethylation of the methoxy perchlorates $\mathbf{1 a}, \mathbf{1 b}$ and $\mathbf{1 c}$ to the corresponding hydroxy ones the polarity changes in the same direction, so it is possible to accelerate the process with a microwave irradiation. Moreover, pyridinium hydrochloride, applied in our experiments, is an ionic liquid which seems to be a useful feature in microwave experiments. The ionic liquids, due to their structure, absorb microwave irradiation efficiently and, in most cases, they exhibit a very low vapour pressure, thereby enhancing their suitability for microwave heating ${ }^{18}$. Kulkarni and coworkers ${ }^{14}$ examined microwave assisted demethylation of variously substituted anisoles using pyridinium hydrochloride. The corresponding phenols were provided with good yield (65 $-95 \%$ ) within the time similar to that obtained by us in conventional experiments (14 - 16 minutes).

In our microwave experiments the volume of the reaction vessel appeared to be an important factor. A glass flask sealed with a glass stopper was used, the volume of which was several times bigger than the reaction mixture capacity. When the smaller flask was being applied, the explosion took place since the highly polar pyridinium hydrochloride reached its boiling point very fast due to the strong absorption of microwaves which caused the pressure increase. The dilution of its vapour with the air, not absorbing microwave irradiation, made the reaction safe.

The reaction time was determined based on UV-VIS absorption spectra of $\mathbf{2 a}$ and then the same procedure was applied to compound $\mathbf{2} \mathbf{b}$. We did not test the microwave demethylation of 1c since the reaction yield in the conventional variant was almost quantitative.

The reaction mixture was irradiated for 1 minute, then was kept in the room temperature and after a few minutes reirradiated. After each series of the irradiation a sample was taken from the reaction mixture and its UV-VIS spectrum in water alkalised with $\mathrm{K}_{2} \mathrm{CO}_{3}$ was recorded (Figure 2). 


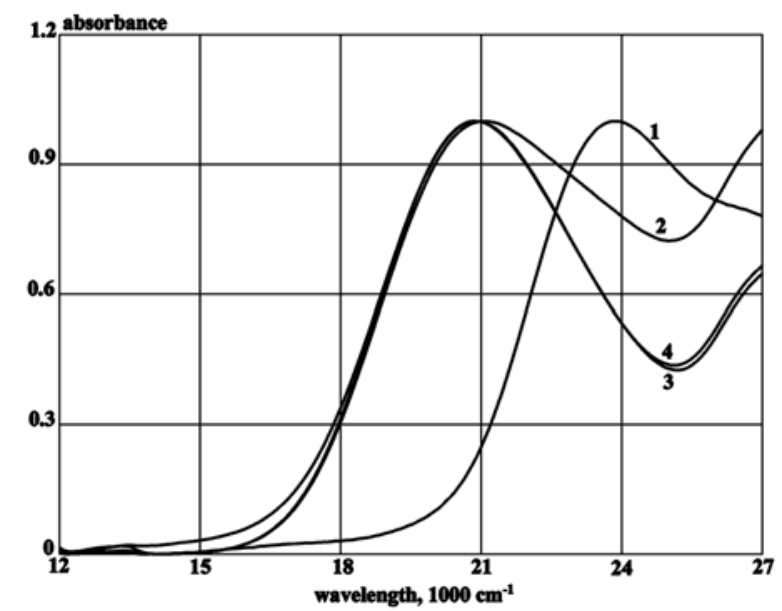

Figure 2. The normalized UV-VIS spectra of $1 \mathbf{a}$ and $\mathbf{2 a}$ after 0 (1), 1 (2) and 2 (3) minutes of irradiation. The curve (4) - spectrum of the product 2a obtained by other method

The analysis of the spectra indicates that only two 1-minute microwave irradiations are sufficient. This reaction time is even shorter than that described by Kulkarni ${ }^{\mathbf{1 4}}$. The reaction yield was almost quantitative. The experiments were conducted in a multi-mode microwave oven, but they were repeated several times giving in every case the same results. The comparative data of the synthesized compounds are shown in Table 2. The structure and formulas of the obtained compounds were supported by physical and spectral data and found to be in good agreement with the target compounds.

Table 2. The comparison data of conventional and microwave demethylation

\begin{tabular}{|l|c|c|c|c|}
\hline & \multicolumn{2}{|c|}{ Conventional heating } & \multicolumn{2}{c|}{ Microwave heating } \\
\hline compound & Yield [\%] & Time [min.] & Yield [\%] & Time [min.] \\
\hline 2a & 84 & 15 & 88.5 & 2 \\
\hline 2b & 72 & 15 & 86 & 2 \\
\hline
\end{tabular}

The application of microwave irradiation in the demethylation of $\mathbf{1 a}$ and $\mathbf{1 b}$ provided further improvements in the synthesis of $7 \mathrm{H}$-indolo[1,2-a]quinolinium solvatochromic dye precursors, especially in the reaction time.

The decrease in the reaction time is especially important in terms of application of a flow microwave reactor. The type of microwave experiments, described in the present paper, was preliminary thus they were conducted on a small scale and in the multi-mode oven. The use of a flow reactor is a way of scaling syntheses. The length of that reactor is determined by the irradiation time. Therefore the reduction of reaction time from 15 to 2 minutes significantly simplifies the construction of the apparatus, in which the solvatochromic merocyanine can be produced on a bigger scale.

\section{CONCLUSIONS}

We have proposed the new method for the preparation of $7 \mathrm{H}$-indolo[1,2-a]quinolinium perchlorates. In comparison with the method previously described in literature the new procedure is high-yielded and very fast, especially when it proceeds under microwave irradiation. The use of pyridinium hydrochloride instead of hydrogen bromide in the demethylation of $1 \mathbf{a}$ distinctly reduced the reaction time and increased the reaction yield. The reaction time shortened over 100 times and the yield of the reaction rose from under $20 \%$ to over $80 \%$. The application of the microwave irradiation allowed to obtain a very good yield in even a shorter period of time.

The new way of the solvatochromic dyes synthesis reduces the cost of their production, which broadens their applicability in different fields of chemistry, biology, medicine, etc.

\section{LITERATURE CITED}

1. Reichardt, Ch. (2003). Solvents and Solvent Effects in Organic Chemistry $\left(3^{\text {th }}\right.$ ed). VCH, Weinheim.

2. Nigam, S., Stephens, M., de Juan, A. \& Rutan, S.C. (2001). Characterization of the Polarity of Reversed-Phase Liquid Chromatographic Stationary Phases in the Presence of 1-Propanol Using Solvatochromism and Multivariate Curve Resolution. Anal. Chem. 73(2), 290 - 297. DOI: 10.1021/ ac000836k.

3. Wróblewska, E.K., Soroka, J.A. \& Rosłaniec, Z. (2005). Solvatochromic dyes in the investigations of polymers' structures. Part II. Diffusion profiles in selected copoly(esterethers). Polimery. 50(4), 286 - 290 (in Polish).

4. Moyano, F., Silber, J.J. \& Correa, N.M. (2008). On the investigation of the bilayer functionalities of 1,2-di-oleoyl-snglycero-3-phosphatidylcholine (DOPC) large unilamellar vesicles using cationic hemicyanines as optical probes: a wavelength-selective fluorescence approach. J. Colloid Interface Sci. 317(1), 332 - 345. DOI: 10.1016/j.jcis.2007.09.051.

5. Tsai, C.C., Lin, H.M. \& Lee, M.J. (2007). Solubility of Disperse Yellow 54 in Supercritical Carbon Dioxide with or without Cosolvent. Fluid Phase Equilibr. 260(2), 287 - 294. DOI: 10.1016/j.fluid.2007.07.070.

6. Thirumoorthi, A. \& Elango, K.P. (2007). Electrochemical oxidation of substituted benzylamines in aquo-acetic acid medium: substituent and solvent effects. J. Chem. Sci. 119(4), $289-294$.

7. Labuszewska, K., Cegielski, R., Niedbalska, M. \& Martynski, T. (2008). Stilbazolium merocyanine systems in Langmuir and Langmuir-Blodgett molecular layers. Colloid Surfaces A. 321(1-3), 39 - 42. DOI: 10.1016/j.colsurfa. 2008.02.039.

8. Zawadzka, I.K., Soroka, J.A., Gąsiorowska, M. \& Sawicka, M.J. (2007). Novel solvatochromic 1,3,2-dioxaborines as composition indicators in analysis of organic solvent mixtures. Chem. Anal. (Warsaw). 53, 83 - 108 .

9. Soroka, J.A. \& Soroka, K.B. (1991). Solvatochromism of dyes. Part I. Solvatochromism of merocyanines. Derivatives of the $7 \mathrm{H}$-indolo[1,2-a]quinolinium system. A new model of solvatochromism J. Phys. Org. Chem. 4(10), 592 - 604. DOI: 10.1002/poc.610041003.

10. Soroka, K.B. \& Soroka, J.A. (1989). Photochemistry of hemicyanines. Part III. Synthesis of 5-(hydroxyaryl)-7,7-dimethyl-7H-indolo[1,2-a]quinolinium perchlorates and determination of their acidities. Chem. Scripta 29, $167-171$.

11. Sawicka, M.J., Soroka, J.A., Wróblewska, E.K. \& Zawadzka, I.K. (2006). Synthesis and UV-vis study of a new strongly solvatochromic merocyanine-like dye with modified donor part. Polish J. Chem. 80, 1337 - 1351.

12. Wróblewska, E.K., Soroka, J.A. \& Soroka, K.B. (2002). Solvatochromism and solvatochromic dyes. Wiad. Chem. 56(12), 113 - 150 (in Polish).

13. Weissman, S.A. \& Zewge, D. (2005) Recent advances in ether dealkylation. Tetrahedron 61(33), 7833 - 7863. DOI: 10.1016/j.tet.2005.05.041.

14. Kulkarni, P.P., Kadam, A.J., Mane, R.B., Desai, U.V. \& Wadgaonkar, P.P.(1999). Demethylation of methyl aryl ethers 
using pyridine hydrochloride in solvent-free conditions under microwave irradiation. J. Chem. Research (S), 394 - 395. DOI: 10.1039/a901278h.

15. Sawicka, M.J., Soroka, J.A., Soroka, K.B. \& Gąsiorowska, M. (2007). Microwaves in organic synthesis. Wiad. Chem. 61(1112), 891 - 911 (in Polish).

16. Medson Electronics, Co Ltd., Poznań - Paczkowo.

17. Perreux, L. \& Loupy, A. (2001). A tentative rationalization of microwave effects in organic synthesis according to the reaction medium, and mechanistic considerations. Tetrahedron, 57(45), 9199 - 9223. DOI: 10.1016/S00404020(01)00905-X.

18. Lidström, P., Tierney, J., Wathey, B. \& Westman, J. (2001). Microwave assisted organic synthesis -a review. Tetrahedron 57(45), 9225 - 9283. DOI: 10.1016/S00404020(01)00906-1. 